\title{
AIRCRAFT PARTICLE INLETS State-of-the-Art and Future Needs
}

by M. Wendisch, H. Coe, D. Baumgardner, J.-L. Brenguier, V. Dreiling, M. Fiebig, P. Formenti, M. Hermann, M. Krämer, Z. Levin, R. Maser, E. Mathieu, P. Nacass, K. Noone, S. Osborne, J. Schneider, L. Schütz, A. Schwarzenböck, F. Stratmann, and J. C. Wilson

\section{Experts discussed how to get aerosol particles into airborne instruments without changing their ambient properties - a still unresolved problem.}

A significant amount of international research is being done to characterize the physicochemical properties (e.g., concentration, size distribution, chemical composition) of aerosol particles and the spatial and temporal distribution of the particles within the atmosphere. Remote sensors cannot directly measure these particle properties and rely on certain assumptions. Therefore, in situ observations are required for validation, such as aircraft particle measurements.
The ideal methodology for making airborne particle measurements is to install the instruments where the air is unbiased by the aircraft and where the sample volume of the instrument is in undisturbed air. The reality of the situation, however, is that many of the important aerosol characteristics, (e.g., light extinction and chemical composition) can only be measured by instruments that are too delicate or aerodynamically unsuited for external mounting. Therefore, investigators bring the air into the cabin with an in-
AfFiliations: Wendisch, Hermann, AND StratmannLeibniz-Institut für Troposphärenforschung, Leipzig, Germany; COE-Physics Department, University of Manchester, Manchester, United Kingdom; BAUMGARDNER-Centro de Ciencias de la Atmósfera, Universidad Nacional Autónoma de México, Mexico City, Mexico; Mathieu And Brenguier-Centre National de Recherches Météorologiques, Météo-France, Toulouse, France; Drelung-Deutsches Zentrum für Luft und Raumfahrt, Flugbetrieb, Wessling, Germany; FIEBIG - Institut für Physik der Atmosphäre, Deutsches Zentrum für Luft und Raumfahrt, Wessling, Germany; FORMENTI-Centre de Geophysics, Universidade de Évora, Évora, Portugal; KRÄMERInstitute für Chemie und Dynamik der Geosphäre I: Stratosphäre, Forschungszentrum Jülich, Jülich, Germany; LEVIN-Department of Geophysics and Planetary Sciences, Tel Aviv University, Tel Aviv, Israel; MASER-enviscope GmbH, Frankfurt am Main, Germany; NACASS-Centre d'Aviation Météorologique, Météo-France/CNRM, Brétigny-sur-Orge,
France; NoONE-Department of Meteorology, Stockholm University, Stockholm, Sweden; OsBORNE-Met Office, Farnborough, United Kingdom; SCHNEIDER-Abteilung Wolkenphysik und -chemie, Max-Planck-Institut für Chemie, Mainz, Germany; SCHÜTz-Institut für Physik der Atmosphäre, J. Gutenberg-Universität, Mainz, Germany; ScHWARZEnBÖCKLaboratoire de Météorologie Physique, Université Blaise Pascal, Aubière, France; WILSON-Department of Engineering,

University of Denver, Denver, Colorado

A supplement to this article is available online (DOI: 10.1175/ BAMS-85-I-Wendisch) CORRESPONDING AUTHOR: Manfred Wendisch, LeibnizInstitut für Troposphärenforschung e.V. (IIT), Permoserstraße 15, D-04318 Leipzig, Germany E-mail: wendisch@tropos.de DOI: 10.1175/BAMS-85-1-89

In final form 28 January 2003 (C)2004 American Meteorological Society 
let that perturbs the sample as little as possible or in a known fashion.

The first problem with this approach occurs if the airborne inlet is situated at a location where the sample is biased prior to entering the inlet. Therefore, it is important to select a suitable mounting position of the inlet in order to avoid the disturbance of air due to the aircraft body itself. Also the inlet should be located outside the aircraft's boundary layer. Furthermore, the sampling is recommended to be isokinetic over the operating envelope of the aircraft. By definition, isokinetic sampling is assured if the velocity vector of the air through the inlet is identical to that of the ambient undisturbed air. If sampling is not done isokinetically, size sorting, heating, and cooling of the aerosol sample occurs due to compression or expansion of the flow, causing physical and chemical changes of the "true" ambient aerosol concentration and composition. Downstream from the inlet tip there may be losses on tubing walls that can remove a significant fraction of the very small particles (with diameters $d_{\mathrm{p}}<\sim 20 \mathrm{~nm}$ ) from the airstream due to diffusion to the walls of the inlet and tubing. Losses of large particles $\left(d_{\mathrm{p}}>1 \mu \mathrm{m}\right)$ may also occur, due to sedimentation, inertial effects, and turbulent deposition. Last, but not least, particle chemical composition and ambient size may change due to the removal of water and other volatile materials as significant heating results from deceleration or direct heating of the inlet.

These problems have been discussed at length in a previous workshop that was held at the National Center for Atmospheric Research (NCAR) in Boulder, Colorado, in 1991 (Baumgardner et al. 1991; Baumgardner and Hubert 1993). A number of significant advances in inlet technology have occurred since that workshop, and new airborne platforms and instruments have become available. Therefore, a review of the current status of inlet technology is appropriate. For this purpose, after more than a decade, a follow-up International Workshop on Airborne Particle Inlets was held in Leipzig, Germany, on 12 and 13 April 2002. This workshop sought to revisit particle inlet-related problems and to review the progress that has been made since the NCAR workshop, as well as to give a recommendation for future needs.

The workshop was organized within the framework of the European Fleet for Airborne Research (EUFAR) project (see information available online at www.eufar.net), funded by the European Union. Within EUFAR several working groups have been established. Two of them, the "aerosol microphysics" and "aerosol chemistry" working groups, initiated this workshop. The workshop was hosted by the Leibniz-
Institute for Tropospheric Research (IfT) in Leipzig, Germany. Those attending the workshop were 28 scientists who work in the field of airborne aerosol measurements and represented research institutes, private companies, and aircraft operators from eight countries (France, Germany, Israel, Mexico, Portugal, Sweden, the United Kingdom, and the United States).

The workshop was split into four thematic sessions: (i) inlet designs, (ii) experimental inlet characterization, (iii) inlet characterization-using models, and (iv) applications. The agenda of the workshop, including the speakers and topics of the talks, as well as summaries of the presentations, are given in a supplement available from the BAMS online archive (http://dx.doi.org/BAMS-85-I-Wendisch).

It became clear from the discussion that a dedicated program of particle inlet system validation must be carried out on all aircraft in a consistent and comparable way. As a consequence, the workshop generally recommends the development of a standard portable reference system to intercalibrate different aircraft inlets. In addition, it is suggested that the use of a simple, externally mounted optical particle counter (OPC) become standard as a minimum aerosol instrument that can measure over a sufficient range of size, such that its measurements can be compared with newly developed instruments or those mounted in the interior of the aircraft. The "reference" OPC, if properly self-characterized, can alert those who are using inlets to measure aerosol size distributions and masses if there is the potential for large particle losses. If a condensation particle counter (CPC) is used as the reference instrument instead it should be taken into account that a CPC is only sensitive to the integral of the particle size distribution, which is dominated by the very small particles and not the large ones, which cause most of the sampling problems. A CPC is not sensitive to the few supermicrometer particles. Thus, a CPC would indicate changes of very small particle losses due to diffusion within the sampling lines only. In this way the CPC data might look very good while the large particle sampling efficiency is poor.

The workshop also made several specific recommendations to the aerosol scientific community, aircraft operators, and funding agencies.

\section{RECOMMENDATIONS FOR THE AEROSOL SCIENTIFIC COMMUNITY. The discussion at} the workshop has shown that active control of the boundary layer can reduce turbulence within the inlets and significantly minimizes large particle losses $\left(d_{p}>1 \mu \mathrm{m}\right)$ in the inlets. For large aircraft, this tech- 
nique [realized in the so-called low-turbulence inlet (LTI); Wilson and Seebaugh (2001)] can be used for sampling of supermicrometer aerosol particles. Currently the LTI cannot be deployed on small- and medium-sized aircraft, due to its power-space needs. Both permanent monitoring of the inlet performance (e.g., pressure, temperature, exit velocity) along the sampling line and numerical calculations of the inlet behavior are needed to design new inlets and to control the passing efficiency of existing inlet systems. Actually, a series of hot-wire measurements could be designed outside and inside the inlet system at the same time to compare, for example, turbulence intensity values and other parameters. Preliminary experiments show that free-stream turbulence intensity values near $2 \%$ and values inside the diffusers between $2 \%$ and $11 \%$ are observed (F. Brechtel 2002, personal communication). If the aircraft was strongly influencing the air turbulence, then the free-stream value should be higher.

Since the 1991 NCAR inlet workshop, there has been significant progress in the area of numerical calculations of the flow field in and around the inlets. It was pointed out at the EUFAR workshop that these need to be extended by the calculation of particle trajectories (Langrangian) and/or particle concentration fields (Eulerian) as well. Characterizing the flow field within and around the particle inlets is the crucial first step. It was also emphasized that the numerical flowfield calculations need experimental validation, for example, using five-hole probes to characterize flow fields at different locations around an aircraft and under widely differing environmental conditions. In addition, easy parameterizations should be derived and existing formulas need to be evaluated with detailed numerical calculations. Furthermore, there is an urgent need for a comprehensive community inventory of available validation, standardization, and calibration tools for airborne aerosol inlets. One suggestion endorsed by modelers and experimentalists alike was the need for a modeling workshop in which the different flow models are intercompared for the same inlet configurations and conditions.

MESSAGE TO AIRCRAFT OPERATORS. Absolute calibration of aerosol sampling systems, including inlets, tubing, and instruments, is extremely difficult. An alternative is proposed with the development of a reference traveling standard pod to be used successively on the research aircraft for intercalibration. The system could be based on an instrumented external pod. Operators are asked to ex- amine if such a pod installation is feasible on their aircraft, whereas the user community will need to seek funding for the development and instrumentation of such reference pods. In addition to the intercalibration objective, an instrumented external pod will be very useful in most of the field experiments. For these developments the aircraft operators need to agree on standard installation and hard points. The workshop participants also recommend that every aircraft should be equipped with a standard minimumrequirement inlet for simple and "standard" aerosol instruments, like an OPC or CPC. Such a system should be installed separated from more sophisticated inlets used for specialized measurements.

MESSAGE TO FUNDING AGENCIES. A comprehensive airborne inlet validation experiment, jointly planned and performed by both modelers and experimentalists, needs to be funded in two steps: a series of experiments utilizing wind tunnel measurements, and airborne validation experiments under a range of atmospheric conditions. In parallel with these two sets of experiments, there should be a workshop in which various inlet models are compared and tested against the wind tunnel and aircraft measurements.

Specific scientific questions require measurements that utilize specific inlet designs; therefore, no one inlet will suit all scientific needs. However, the most important result of the workshop was that the discussion among the scientists on particle inlet-related problems has been revived with a general interest and motivation to address the practical issues of the aircraft operators and scientific community.

ACKNOWLEDGMENTS. Funding of the workshop by EUFAR is appreciated. Fred Brechtel provided useful comments on the manuscript. Heike Scherf and Ariane Pohlenz from IfT and F\&U confirm, respectively, helped in organizing the workshop.

\section{REFERENCES}

Baumgardner, D., and B. Huebert, 1993: The airborne aerosol inlet workshop: Meeting report. J. Aerosol Sci., 24, 835-846.

- — - , and C. Wilson, 1991: Meeting review: Airborne aerosol inlet workshop. NCAR Tech. Note NCAR/TN 362+1A, 288 pp.

Wilson, J. C., and W. R. Seebaugh, 2001: Measurement of aerosol from aircraft. Aerosol Measurement, $2 \mathrm{~d}$ ed. P. Baron and K. Willeke, Eds., John Wiley \& Sons, 887-901. 


\section{CAMbridge}

\section{What's New in Atmospheric Science?}

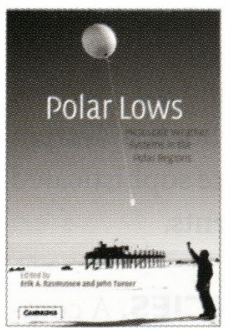

Polar Lows

Mesoscale Weather Systems in the Polar Regions

Edited by Erik $A$. Rasmussen and John Turner

Provides an in-depth review of our understanding of the small, high latitude weather systems known as polar lows, and describes the climatological distribution of these depressions.

$\$ 120.00$ : Hardback: 0-521-62430-4

\section{Lightning}

Physics and Effects

Vladimir A. Rakov and Martin A. Uman

Covers essentially all aspects of lightning, including lightning physics, lightning protection, and the interaction of lightning with a variety of objects and systems as well as with the environment. \$200.00: Hardback: 0-521-58327-6
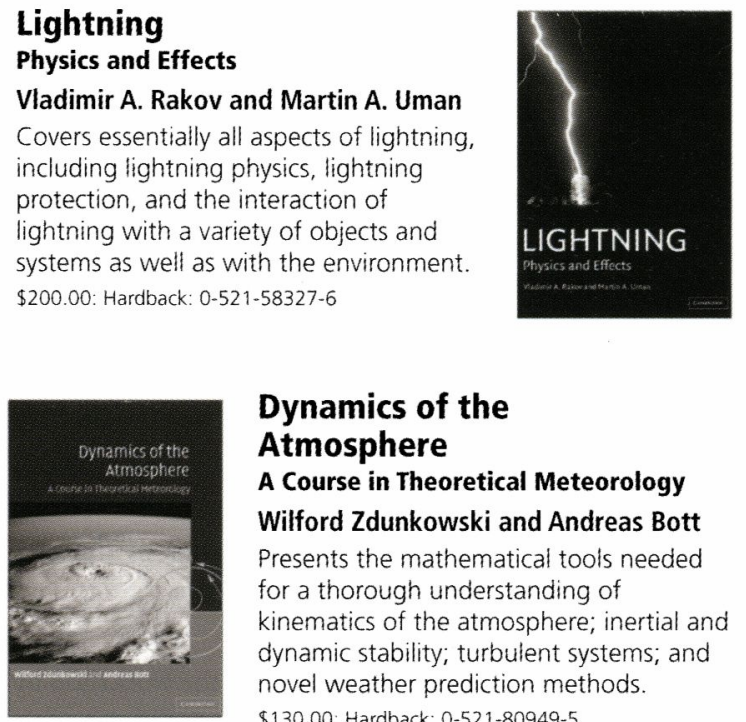

\section{Dynamics of the Atmosphere}

A Course in Theoretical Meteorology Wilford Zdunkowski and Andreas Bott Presents the mathematical tools needed for a thorough understanding of kinematics of the atmosphere; inertial and dynamic stability; turbulent systems; and novel weather prediction methods.

\$130.00: Hardback: 0-521-80949-5 $\$ 60.00$ : Paperback: 0-521-00666-X

\section{Mass Balance of the Cryosphere}

Observations and Modelling of Contemporary and Future Changes

Edited by Jonathan L. Bamber and Antony J. Payne

Offers a comprehensive overview of the significance of the glaciers, ice caps and ice sheets of Antarctica and Greenland. $\$ 130.00$ : Hardback: 0-521-80895-2

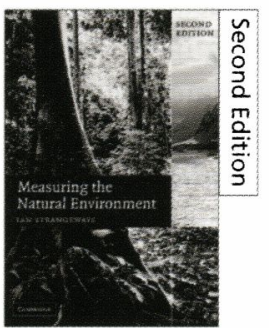

\section{Measuring the Natural Environment} lan Strangeways

"The book is highly recommendable. very well written, concise and clear." -Environmental Geology

\$120.00: Hardback: 0-521-82205-X \$70.00: Paperback: 0-521-52952-2

\section{Global Change and Local Places}

Estimating, Understanding, and Reducing Greenhouse Gases

Edited by The Association of American Geographers-GCLP Research Team Examines the causes and effects of climate changes triggered by human activities. \$75.00: Hardback: 0-521-80950-9
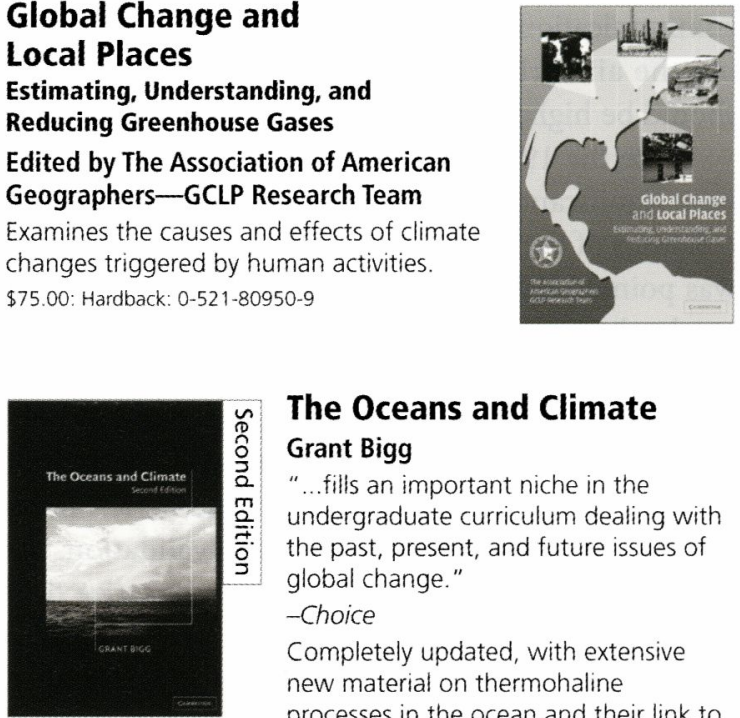

The Oceans and Climate Grant Bigg

"...fills an important niche in the undergraduate curriculum dealing with the past, present, and future issues of global change."

-Choice

Completely updated, with extensive new material on thermohaline processes in the ocean and their link to both abrupt and longer-term climate change.

\$100.00: Hardback: 0-521-81570-3 \$50.00. Paperback: 0-521-01634-7

Weather Cycles

Real or Imaginary?

William James Burroughs

Provides a different perspective on one of the most difficult questions in the current global warming debate: how much of the recent temperature rise can be attributed to natural causes? $\$ 100.00$ : Hardback: 0-521-82084-7 \$45.00: Paperback: 0-521-52822-4

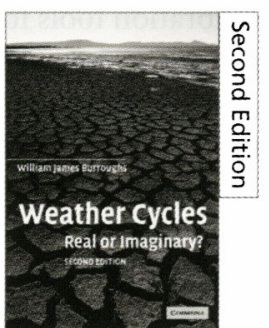

